\title{
Aproximació a un ensenyament de literatura (nord) catalana: l'oralitat en Jordi Pere Cerdà ${ }^{1}$
}

\author{
Josep Marqués Meseguer (j.marques.meseguer@gmail.com) \\ Universitat de Perpinyà Via Domícia
}

\section{Sobre l'ensenyament i el pensament poètic}

L'ensenyament, en qualsevol disciplina i nivell acadèmic en què s'exercisca, esdevé cada cop més una experiència interactiva encaminada a establir un vincle genuí entre l'objecte d'estudi, l'estudiantat i el medi que els influencia. L'alumnat i el professorat, l'un amb l'altre, exploren vies cap a una comprensió del món i de si mateixos. Aquest procés d'aprenentatge integral, en podríem dir, es basa a fer possible, de manera planificada i per tant conscient, que els coneixements adquirits siguen viscuts com a experiències reals (significatives, autèntiques) en el desenvolupament de l'individu i del collectiu.

Perquè aquest caràcter real siga interpretat i sentit com a tal, cal d'entrada que el procés d'aprenentatge es construïsca sobre les pròpies necessitats i pertinences dels alumnes, i sobre les seues estructures cognitives i afectives existents, tal com assenyala l'etnògraf Peter Woods (1993: 4). Això implica entendre l'aprenentatge, en primer lloc, com un procés obert que es construeix de manera negociada (1993: 4) entre l'estudiant i el professor, cosa que els mena a reconèixer-se com a subjectes cooperadors, interdependents i per tant actius i responsables en aquest camí compartit d'exploració intel-lectual i emocional. I en segon lloc, també comporta entendre que el diàleg crític (1993: 21) establert entre ambdós ha de veure's completat amb aquell que efectuen amb l'entorn. L'entorn és el context d'aprenentatge que interactua amb l'espai educatiu més immediat de l'establiment, el qual s'incorpora al món real en el moment que s'inicia un diàleg entre ells: «the world, city or village is the school» (1993: 10).

Aquest enfocament crític de l'aprenentatge es podria definir, atesos els paràmetres anteriors, com un procés cognitiu de cerca, conduït per diversos agents (professors i estudiants sobretot) $\mathrm{i}$ en el qual interactuen factors socials, emocionals i culturals que conformaran les identitats dels aprenents. Teixir aquestes experiències crítiques en el camp educatiu, com les defineix Woods, significa assumir el rol de l'investigador, i per tant del creador, a fi d'adquirir el propi aprenentatge. És insistir a forjar pensadors autònoms, que s'interroguen més sobre com conèixer, que sobre què conèixer (4); en paraules de Bonnet (citat per Woods), és insistir en la importància del pensament poètic, el qual:

seeks harmony rather than power, receptiveness rather than imposition, is affected rather than effective, is openly curious and wondering rather than goal-oriented, accepts mystery

\footnotetext{
${ }^{1}$ Aquest article s'ha realitzat dins del marc del projecte d'investigació AICO/2015/041. Personatges, identitats socials i territori a la literatura valenciana dels anys seixanta al canvi de segle.
} 
as against seeking transparency, intuits the wholeness of things as against analysing them into specific problems to be solved, and stays with things in their inherent strangeness rather than turn them into defined objects [...]. In essence, poetic thinking attempts to re-establish a direct living in, and with, things (1993: 5-6).

El pensament poètic, tal com ací s'entén, no se circumscriuria únicament a l'ensenyament de les matèries artístiques o humanístiques sinó que podria abastar qualsevol disciplina (6), per bé que les ara citades (on s’inscriu la literatura, que atén el nostre article) puguen tenir una major tradició a l'hora d'acollir diferents mètodes de coneixement. De fet, en el seu sentit original, poètic (del verb grec poiein) és tot allò que es crea o es fa, que s'inventa i que per tant innova a l'hora de posar en relació idees que després es podran articular i comunicar mitjançant el llenguatge. Ben aviat, però, en la mateixa antiguitat grega, el concepte de poesia s'acotarà i començarà així a descriure el delit per utilitzar el llenguatge. S'insistirà així en la recreació verbal en tant que experiència estètica, fins al punt que es reconeixerà socialment la necessitat humana de disposar de la paraula de manera clara, forta i inspiradora, fruit d'una elaboració innovadora, la de l'autor (del verb llatí augere, augmentar la sensació de vida), la de l'artista (Cayeux, 1997).

Partir doncs de la poètica a l'hora de concebre un ensenyament ens permet situar al bell mig de l'aula la llar del foc creatiu, tot relacionant les persones i les coses des del punt més radical, i així vital, de l'experiència humana. Situat el llenguatge com a motor de creació i interacció amb el medi, l'oralitat s'erigeix al seu torn com el mitjà d'expressió originari i directe a l'hora de relacionar-nos i per tant de generar coneixement i cultura, un element clau, a la fi, en aquest restabliment de la vivència directa amb les coses a què es referia Bonnet, i amb nosaltres mateixos.

Fins ací hem traçat una breu aproximació teòrica al pensament poètic que ens permetrà de situar dos dels seus elements clau, oralitat i espai, en el nostre propòsit d'aportar algunes notes sobre la vida i l'obra de Jordi Pere Cerdà. Aquestes notes, assumint el mateix rol de l'investigador que esmentàvem adés, podran servir d'hipòtesis de treball a l'hora de planificar, de manera preliminar, un ensenyament de literatura catalana a la Catalunya del Nord. L'envit, doncs, no serà altre que fer dialogar la creació del nostre autor amb el medi social d'aprenentatge que situem i que és el propi del mateix Cerdà.

Així, abordarem primerament el desvetllament de la poesia en Cerdà i el desafiament lingüístic, cultural i territorial que haurà d'encarar com a autor nord-català. Seguidament, ens referirem al pes de la cultura oral i la seua relació amb l'entorn des d'una atenció al folklore i a l'etnopoètica. Per fi, mostrarem alguns exemples literaris on l'autor introduí aquests elements de la memòria oral, i on es fonen l'espai cerdà ${ }^{2}$ amb la construcció del seu propi món literari cerdanià.

\footnotetext{
${ }^{2}$ Al llarg del text, usarem l'adjectiu cerdà (en minúscula) com el relatiu o pertanyent a la comarca de l'Alta Cerdanya (la part sota administració francesa) o a la comarca completa de la Cerdanya (tant la part francesa com l'espanyola); en canvi, usarem el nom propi Cerdà (en majúscula) per referir-nos a l'autor que tractem (Jordi Pere Cerdà, pseudònim literari d'Antoine Cayrol) i l'adjectiu cerdanià per tot allò que corresponga a aquest mateix autor.
} 


\section{La revelació de la poesia en Cerdà i el desafiament lingüístic}

Jordi Pere Cerdà (1920 - 2011), pseudònim d'Antoine Cayrol, és un autor, en paraules de Pere Verdaguer, amb «una immensa cultura d'autodidacte, la millor per a un poeta $\mathrm{i}$ escriptor» (1966: 11). Cayrol lamentà, però, no haver cursat estudis universitaris ni haver viscut l'ambient d'agitació intel·lectual pròpia de l'acadèmia. ${ }^{3}$ Natural de Sallagosa, a l'Alta Cerdanya, el seu context de vida serà fins al 1960 (moment en què s'instal-larà a Perpinyà) ${ }^{4}$ el de la pagesia, els ramaders i els pastors. «Però, esperit curiós i sensible, llegí tot el [que li] queia a les mans, encara que els llibres fossin més aviat rars a Cerdanya» (Balent, 2011: 72). Des de ben jove, sentí com l'afecció per la lectura el distanciava de la societat rural cerdana alhora que l'encaminava cap a un autoaprenentatge forjat en la intimitat:

L'escrit em feia diferent dels nens del meu temps. Cap d'ells hi portava interès; em sentia una mica estrany, potser i tot, una mica vergonyós. Més tard, sentiré amb una certa angoixa com el meu gust pel llibre em va apartant de la joventut del meu poble. És a través d'aqueix sentiment que naixeré a l'experiència de la solitud existencial amb què tot home topa un dia o altre; allò que se'n diu la diferència. Tot això és viscut a dins la boira, l'encegament, els jocs, l'instint del plaer, la incertitud i l'angoixa de tot (Cerdà, 1988: 7).

Aquesta diferència o solitud existencial sentida i viscuda per Cerdà de manera crítica serà fonamental en el seu procés d'aprenentatge autodidàctic; al capdavall, «la culture est d'abord une conception de soi; il n'y a pas de culture sans travail sur soi» (Cayeux: 1997). En aquesta descoberta de si mateix a través dels llibres, el seu pensament poètic es desvetllarà, a tall de xoc, arran de la descoberta de la poesia de Pierre Seghers (1906 1987), una poesia que, en paraules de Cerdà, «n'était pas romantique, ni parnassienne, ni classique à la manière de Ronsard, c'était une poésie qui me parlait... Il m'a semblé que soudain, une partie du monde venait me parler à voix douce au creux de l'oreille». ${ }^{5}$ Així, el mateix distanciament de la ruralitat cerdana que li crea la seua aproximació a la cultura llibresca, li permetia ara acostar-se al món per mitjà de la configuració de la seua pròpia idea poètica. Però, el distanciament amb la realitat continuarà sent necessari per gestar l'autor i així fer aflorar la creació:

\footnotetext{
${ }^{3}$ A Cant alt. Autobiografia literària, Cerdà reconeix, però, que «el cas de viure lluny de les ciutats i en defora de grups culturals m'ha ajudat a escapar al risc de teorització que naix de les discussions dels nuclis; puc posar-ho igualment a càrrega d'un temperament que porta més cap al social i a l'experimentació humana, que no és sensible a les seduccions (que reconec necessàries) del conceptualisme abstracte» (1988: 237).

${ }^{4}$ Installlat a la capital rossellonesa, Cerdà treballarà primerament de carnisser, ofici al qual ja es dedicava a Sallagosa, per passar a dirigir, entre 1964 i 1976, la Llibreria de Catalunya (actual Llibreria Catalana), fent de llibreter i animador literari i cultural. A partir de 1980 tornarà a la Cerdanya alternant la vida entre Sallagosa i Perpinyà.

${ }^{5}$ En l'article de Bernard Rieu «Un poète en prise directe avec son temps» (p. 8), inclòs al llibret dedicat a Jordi Pere Cerdà publicat per l'Amicale des Anciens d'Arago, del liceu perpinyanès Francesc Aragó, on Antoine Cayrol cursà tres cursos en l'aleshores collegi (centre de primer nivell d'ensenyament secundari). El llibret és consultable en línia: <http://anciensdarago.com/promotion.j.p.cerda.2012.2015-363600-3-14-71.php>.
} 
Devia començar a treballar a l'escorxador i servir darrere el taulell, a catorze anys. L'ofici m’obligava a viure a nivell de la gent i dels seus problemes diaris; teníem a casa pastor i criada; pagesos petits venien a fer jornals a la temporada de l'herba, més tard s'hi afegiran vaquer i mosso. I no em sentia mica dins la pell d'un carnisser, ni d'un pastor, ni d'un pagès. Ho he fet! He matat, he escorxat, esquarterat, detallat, he guardat, he llaurat, dallat, segat, carregat la carreta, he molsit. Ho he fet sense cap disgust, sensible potser a l'esforç muscular que representava, sensible sobretot a la xarxa de relacions humanes a què m'obligava; però sempre amb una part de mi, absenta [...]. Tot anhel de cultura representava, per a mi, una voluntat, potser una evasió del món real on em movia [...]. Vaig posar entre el món real i jo una distància, una visió estètica (Cerdà, 89, 90, 106).

Arran de les activitats d'Antoine Cayrol com a resistent durant la Segona Guerra Mundial, ${ }^{6}$ Cerdà es relacionà amb Seghers, amb el qual mantingué contacte per correspondència que aprofità per fer-li arribar els seus primers poemes, escrits en francès. Arran de les correccions fetes pel poeta parisenc, Cerdà s'adona que la seua expressió en francès no es troba a l'altura de la seua intuïció poètica (Vinas, 2000: 12). Si bé la cultura racional, fruit de la formació reglada que havia adquirit el poeta de Sallagosa, era majoritàriament francesa, la seua cultura empírica, la familiar i la dels seus veïns de la rural Cerdanya, era plenament catalana. Potser és en aquest punt que Cayrol s'adonà que «una llengua no és tan sols un instrument de pensar i dir, sinó que va lligada molt més profundament amb les arrels del nostre ésser» (Cerdà, 1988: 61). Davant l'espai polític evident, que traça el poder per mitjà d'institucions i precisos límits fronterers, ${ }^{7}$ Cerdà començà aleshores a intuir i a valorar l'existència de tot un altre espai poètic, governat per unes emocions amb dimensió illlimitada i que, en tot cas, en l'àmbit més tangible com és el territori, es reconeixia en l'expressió d'una llengua catalana, nord-catalana, «repliée dans des contraintes dialectales» (1997: 9).

Decidit a usar la llengua que millor responia a les dimensions de la seua capacitat poètica, Cerdà s'anà formant «una consciència de catalanitat» fruit «d'una voluntat d'escriure» (1988: 23); però com escriure en una llengua apresa només d'oïda? «Si je le possède [el català] au point de vue oral, là j'ai un problème que la société a mis des siècles à résoudre, c'est le passage de l'oralité à l'écriture [...]. Il faut que j’invente une poésie que je n'ai pas devant moi, que personne n'a» (Vinas, 2000: 13).

De fet, el repte poètic i lingüístic que encarava Cerdà era doble: les seues limitacions per emprendre una expressió poètica raïen no només en la seua manca de cultura escrita en català, sinó també en el fet que aquesta cultura, tenint Barcelona com a principal referència en la creació de l'estàndard, situava l'espai cerdà (del costat francès especialment, i per extensió el nord-català) en una dimensió extraterritorial pel que fa a l'aplicació d'aquesta

\footnotetext{
${ }^{6}$ En essència, Cayrol s'encarregà d'assegurar la travessada cap a Espanya, a través de la frontera pirinenca, de fugitius de la França de Vichy i de l'ocupació alemanya. Aquesta tasca li valgué, entre altres reconeixements, la condecoració de la Croix de Guerre avec Étoile d'Argent del govern provisional de la República Francesa. A Finestrals d'un capvespre (2009, Perpinyà, Trabucaire), Cerdà explica la seua experiència en la Resistència francesa.

${ }^{7}$ Encara més evidents a llocs com la Cerdanya: «El país fronterer cria tota una jerarquia de professionals, el que porta barret, botiga, puro i cotxe, i el que porta el paquet; hi havia el contrabandista d'ocasió, el de circumstància i el d'atzar (1988: 17).
} 
codificació lingüística, cosa que dificultava la integració i l'articulació de l'àmbit cultural català. Així, entre el català oral cerdà del poeta i el català escrit estàndard «de Barcelona», semblava haver-hi una distància insalvable que confrontava dos mons: la voluntat poètica de Cerdà d'aplegar en català la seua cultura d'autodidacte, davant la realitat política de frontera que no actuava sinó com a força disgregadora d'aquesta catalanitat. Cerdà, amb tot, semblava decidit a salvar tots els obstacles per mitjà de l'acte poètic, aquella activitat humana que menys entén de límits:

Si hagués acceptat de viure d'esquena a la paret, vull dir d'esquena a la frontera, com ho volia la mentalitat que em voltava, la mentalitat que comandava la societat on vaig entrar al nàixer al món, els colors haurien estat diferents. Ben senzillament, haurien estat altres! La impossibilitat és de seguir diverses vies al mateix moment, si no és en poesia (Cerdà, 1988: 221).

\section{L'oralitat en Cerdà: folklore i etnopoètica}

«L'émotion que je ressens, je la dois aux choses d'ici... "Si j'écrivais ce langage parlé, si j'écrivais notre langage...”” (1992: 42). Així s'expressa Charles Ferdinand Ramuz, poeta suís en llengua francesa que es troba en un dilema paral·lel al de Cerdà (Carrera, 2012) pel fet d'haver de triar entre escriure en francès, una llengua estàndard apresa per escrit i sense el vehicle de les emocions, o bé en català, una llengua popular apresa oralment $\mathrm{i}$ sense el vehicle de la norma. Com apuntàvem adés, el factor extraterritorial permet copsar les dificultats d'ambdós poetes a l'hora de trobar un canal adequat per a la seua expressió literària ${ }^{8}$ unes dificultats que, com veurem, Cerdà superarà introduint en la llengua poètica el seu català cerdà. ${ }^{9}$ I per fer-ho possible, no només s'apropà a la lectura dels clàssics catalans, sinó que també es reapropà al patrimoni oral transmès en la llar familiar, font primera de coneixement per al poeta que li permeté començar a nodrir els seus «somnis» i la seua «imaginació»:

Quantes [històries] han alimentat els meus somnis quan escoltava l'àvia, una orella penjada als seus llavis i els ulls fixats sobre un llibre. No em vaig adonar mai que l'àvia o la mare m'expliquessin el món que girava entorn nostre, potser es va fer escoltant les seves enraonades, potser es tracta d'una mena d'observació que porti a les coses, a sota el vagar de la imaginació (Cerdà, 1988: 15).

Observem com Cerdà aprecia la funció educativa o valor formatiu de les històries orals i de les converses presenciades ${ }^{10}$ però no només: el fet que aquestes històries alimenten els somnis del futur poeta ens permet intuir que l'acte comunicatiu, a més de tenir un

\footnotetext{
${ }^{8}$ Més encara quan l'espai nord-català es trobava en bona mesura incomunicat amb el sud-català arran de la postguerra espanyola i de la consegüent repressió pública de la cultura catalana.

9 «Cerdà va s'affranchir des contraintes «classiques», et y faire entrer son catalan septentrional» (Carrera, 2012: 565).

${ }^{10}$ També: «Je me suis mis à écouter les autres [...]. Et alors je me suis rendu compte chez ma mère même avoir appris des mots que je ne lui avais jamais entendu dire! Et chez les voisins, je pourrais vous dire: tel mot, c'est une telle qui me l'a dit la première fois. Le nuage, on disait «bruma», on ne disait pas un «núvol», mais on disait aussi «ennuvolat» (Vinas, 2000: 14).
} 
aspecte actiu (el fet de contar una història), també té ací un caràcter estètic (contar la història de manera artística, més enllà de la voluntat d'informar). Tots dos aspectes seran inherents a la definició de folklore, segons la concepció de Dan Ben-Amos: allà on la gent es comunique de manera directa i s'expresse artísticament, hi haurà folklore (Oriol, 2002: 22-23), generant en cada moment actes únics, irrepetibles (27) i, amb aquests, una visió del món, una cultura, singulars.

Talment com en el context familiar, Cerdà començà a prestar també atenció al saber (lore) dels seus veïns, la gent (folk) cerdana:

Vaig trobar el poble portador d'una memòria encara viva de la cultura oral, lingüística i cantada. Vaig posar-me a fruir d'aquell bé amb una dèria, amb un goig tant i més fort, que ell alimentava de forma viva la meva recuperació de la llengua que havia començat amb els llibres (Cerdà, 1988: 70).

Cerdà esmenta ací la continuïtat espontània («encara viva») que troba en el saber dels seus veïns, el qual és un altre dels elements definitoris del folklore segons Josep Martí (Oriol, 2002: 37). També fa referència a una «cultura» popular («el poble») i tradicional («memòria»), dos termes que, segons Oriol, poden caracteritzar el folklore però sense arribar a definir-lo per se, ja que depassen àmpliament el seu àmbit (27). En canvi, el component «oral» ens permet dirigir la tasca de coneixement folklòric de Cerdà cap a una anàlisi etnopoètica, ja que aquesta es defineix com una manifestació artística de base verbal que produeix la gent en un procés d'improvisació (39).

La connexió emocional de Cerdà amb aquestes produccions etnopoètiques cerdanes fou tan intensa que no només decidí recollir-les, sinó també començar a reinterpretarles. El «món real» del qual s'havia distanciat en un primer moment per poder gestar el seu pensament estètic (Cerdà, 1988: 90, 106), esdevenia ara l'aliment fonamental del seu procés creatiu. S'estableix així una reconciliació (Carrera, 2012: 570) de l'individu amb el seu entorn que, com veurem més endavant, assolirà la comunió creativa entre llengua popular i llengua literària.

Vaig tenir el sentiment de la presència amagada del nostre vast cançoner l'any 1946. El nostre grup de teatre comprenia algunes veus boniques, cantàvem camilleres i donàvem preu al cant. Eren cançons absolutament desconegudes per a nosaltres. Les vàrem aprendre, les vàrem cantar i heus ací que les cançons van trobar un ressò en diverses persones del públic. Ens ho van venir a dir: aqueixa ma mare la cantava, aqueixa un tal, aqueixa una tia, totes, totes, quedant amagades de la pràctica quotidiana, estaven presents en una o altra persona del poble, $i$, sense el xoc que va despertar la nostra presentació, ho serien encara (Cerdà, 1988: 71).

Malgrat la continuïtat en la pràctica folklòrica cerdana que comentàvem més amunt, en aquest fragment Cerdà atesta que la transmissió del folklore s'ha interromput: als anys quaranta, les camilleres ${ }^{11}$ eren cançons «amagades» perquè ja eren «desconegudes» per als joves cerdans de la generació del nostre autor. És per aquest motiu que, més que continuïtat

${ }^{11}$ També conegudes com caramelles, són cançons populars que canten les colles per a la celebració de la Pasqua. 
en el folklore, ens trobem davant la «voluntat de continuïtat» (Oriol, 2002: 37) de Cerdà per recuperar aquest folklore que desapareixia dels seus contextos d'ús. És, al capdavall, la tasca del folklorista: quan es perd l'expressió espontània del folklore, el folklorista, havent generat una consciència de tradició, «transporta i adapta elements tradicionals a nous espais i a nous temps» (37). Així, a Cerdà, el pensament poètic i el desig d'escriure li feren redescobrir el folklore de la Cerdanya, el qual valorarà de manera positiva i tractarà de revitalitzar tot introduint-lo en la seua incipient activitat teatral. Evidentment, la tasca del folklorista no seria possible sense una adaptació de la tradició als nous contextos (i per tant sense una certa manipulació); «per això, els productes del folklore són imperfectes mentre els del folklorisme presenten un aspecte més elaborat» (37) i, per això mateix, les representacions teatrals de Cerdà causaren impacte entre aquells que encara conservaven la vivència del folklore.

\section{Recreant la memòria: d'art verbal a literatura}

La interrupció en la transmissió del folklore es trobava en una fase tan avançada que el que Cerdà pogué recollir era ja molt reduït, vorejant el precipici de l'oblit ${ }^{12}$ : «la veu oral ho ha dut fins a mi, quasi a punt de perdre's, i amb una formulació massa esquifida, per transcriure-la tal qual» (Cerdà, 2001: 11). Li «calia inventar» (13) per poder tornar a la gent aquest saber que tant li havia ensenyat, fet gaudir i inspirat el seu pensament poètic. Li calia, a la fi, mantenir viu aquest diàleg amb el seu entorn cerdà, ara amb la pulsió de l'escrit: «en realitat avancem si hi ha un diàleg que s'instaura entre el públic i l'intel·lectual, si l'escriptor accepta la part de didactisme que entra en el seu paper d'escriptor» (9-10).

Amb el canvi en el context de transmissió, canviava també la natura del saber: el producte etnopoètic desapareixia per donar pas a una obra literària de base folklòrica. El missatge continuava sent artístic (i per tant literari), però la fixació escrita desfà el seu caràcter oral, improvisat, directe i anònim. Jordi Pere Cerdà, autor, exercirà doncs de folklorista i literat alhora: recol·lector, transcriptor i (re)creador. Segurament a contracor, forçat per les circumstàncies, ja que Cerdà, com hem vist, es planyia de la pèrdua de la cultura oral que tant apreciava ${ }^{13}$.

L'element etnopoètic es troba present en tota la producció literària de Cerdà (la qual comprèn poesia, teatre i narrativa). Per exemple, al recull de novel·les curtes Col·locació de personatges en un jardí tancat, hi trobem fraseologia, com ara parèmies («»El món és un fandango», deia l'àvia»; Cerdà, 1993: 185), i cançons:

I en abaixar les parpelles li va arribar la cançó de la mare: De la soca naix la rama, de la rama naix la flor. Desitjada cançó que mai més no havia recordada. Quina meravella li portava ara: de la flor ve el teu somriure, del somriure la cançó. Dels llavis de la dona sortia la flor del cant» (131).

\footnotetext{
12 «Llavors que en la quasi totalitat de les comarques catalanes, es trobaren a començament del passat segle, devots de la cultura o de la llengua, sinó de la vida social, per recollir els testimoniatges de la riquesa popular oral, aquest caire d'activitat va quedar aquí quasi sense servidor» (Cerdà, 2001: 10).

${ }^{13}$ Aquest valor que l'autor atorga a la vivacitat de la cultura oral no s'oposa al seu interès per poder passar, en català, de l'oral a l'escrit, ja que per Cerdà «la liberté d'une langue c'est son écriture» (Vinas, 2000: 13).
} 
Contalles de Cerdanya (1961) és però l'única obra en què el nostre autor reprèn de manera íntegra la tradició oral cerdana dins els paràmetres del folklorista-literat. En aquesta, Cerdà reelabora rondalles i llegendes que conegué de primera mà (o cassos, com les anomenen les seues informants) per dotar-les d'una forma literària que les faça aptes per a la lectura del públic al qual s'adrecen (Oriol, 2011: 97). Al pròleg, Cerdà pren cura de citar les seues «dictaires» (2001: 10) i també d'advertir el lector que en cap cas «provo de fer meu el que no me pertany, la part original d'aquestes obretes, és seu pròpiament» (11). Aquests elements mostren com l'autor tractava d'acostar-se més al vessant de folklorista que no al de literat, per més que es veurà forçat a fer més de rondallista recontador que no de rondallista transcriptor (Oriol, 2011: 98) a causa de la poca extensió de les rondalles recollides.

Davant la necessitat de recrear l'oral en l'escrit, «el procés de nova redacció [...] no suposa una tasca gens fàcil per al literat-folklorista ja que li cal trobar l'estil adequat per transmetre els relats que són vius en la tradició de forma que no perdin el seu caràcter» (Oriol, 2011: 98). Cerdà, vinculat ja de manera visceral al patrimoni cultural cerdà en el moment de redacció d'aquestes rondalles, frisava per «autentificar als ulls del públic [...] la part viva, rica [...] que demorava amagada a sota l'actualitat social, econòmica, política» (2001: 10). L'estil de Contalles que en resultà, segons Albert Manent, serà «poètic i literari, popular i senyorívol» (1961: 7), optant així per un model de llengua que feia equilibrar els principis normatius amb la vivacitat dialectal de l'idioma (Oriol, 2011: 102). Cerdà, per mitjà d'aquest estil que aconseguia enllaçar el culte amb el popular, restituïa la dignitat de la seua gent cerdana i de les seues produccions etnopoètiques: «la gent que posseïa una llengua a punt de jugar amb els mots, els matisos, els fets culturals reinventats, aqueixa gent no es pot considerar de cap manera com a gent pobra» (Cerdà, 1988: 85).

A Contalles de Cerdanya, com hem vist, aflora la voluntat de l'autor de mostrar que el folklore cerdà, tot i les dificultats de la seua pervivència, era una força viva, bategant. A la llegenda «La dona d'aigua de Lanós» que encapçala la darrera edició de les Contalles (2001), s'observa per mitjà del meravellós el símbol d'aquesta força subtil i tel·lúrica que remou l'espai cerdà:

[Les dones d'aigua] reien, cantaven, illuminaven l'aigua amb les seves mirades, jugaven amb les onades, de vegades amb una bromassa fonedissa que s'aixecava de l'estany a l'hora quieta del crepuscle, els cossos de les dones semblaven enlairar-se barrejats amb la boira, amb els fils llanosos que sortien de l'aigua [...] L'aigua de l'estany anava plena de vida [...]. L'aigua de l'estany tan apacible, tan fredosa i austera quan l'espiàveu de lluny, l'aigua de l'estany vista d'a prop i observant-la l'ull amb atenció i la cura que es mereix, l'aigua de l'estany tenia la força d'un viver (Cerdà, 2001: 19).

\section{Conclusions}

El pensament poètic de Jordi Pere Cerdà està lligat de manera indestriable a la redescoberta del folklore de la seua Cerdanya natal, el qual aconseguirà dignificar per mitjà de la seua creació literària. La seua experiència de vida és la d'un autor autodidacte que aprendrà de manera crítica, això és, qüestionant-se la seua situació en el món d'acord a 
la seua cultura llibresca francesa i a la seua cultura oral catalana pròpia de l'Alta Cerdanya. Aquest treball sobre si mateix li ha permès de desenvolupar una formació intel·lectual i una mirada estètica que acabarà projectant, per mitjà de la creació literària, sobre el seu entorn cultural més immediat, la Cerdanya, font inesgotable d'emocions i imaginació per a l'autor. Així, les notes biogràfiques que hem aportat sobre el poeta de Sallagosa considerem que poden servir per plantejar hipòtesis de treball a l'hora d'enfocar un estudi de literatura catalana a la Catalunya del Nord que, com també el recorregut de Cerdà, puga ser crític, creatiu i en interacció directa amb el seu entorn. En síntesi, proposem un ensenyament que siga part de la vida mateixa, tal com Cerdà establí un «compromís biològic» amb el conreu d'una paraula poètica que poua en el passat per projectar-la en el futur:

«L'impuls de l'escriptura literària és per a alguns dels seus participants un joc amable, un luxe de l'intel-lecte i de la imaginació, un distanciament -lúdic i lúcid-respecte a la vida. Per a alguns, a més d'això, hi ha una altra cosa: l'addicció a la literatura com una mena de «compromís biològic amb la lletra»» (Salvador, 2012: 167).

\section{BIBLIOGRAFIA}

BAlent, A. (2011): «Antoni Cayrol [Jordi Pere Cerdà], una aproximació biogràfica», BADosa, C. i D. Bernadó (eds.): Aïnes noves, 3, Perpinyà, Premses Universitàries de Perpinyà, 71-82.

CArrera, H. (2012): «Charles Ferdinand Ramuz et Jordi Pere Cerdà, deux transbordeurs «du parlé à l'écrit», de la culture populaire à la Littérature savante», dins CourrénT, M.; G. JAY-RoberT i T. ÉLOI (coord.), Transports, Mélanges offerts à Joël Thomas, Perpinyà, Premses Universitàries de Perpinyà, 559-572.

Cayeux, J.P. (dir.) (1997): Kenneth White: du nomadisme à la géopoétique, Centre Départemental de Documentation Pédagogique de l'Eure (vídeocasset en format VHS).

CERDÀ, J.P. (1988): Cant alt. Autobiografia literària, Barcelona, Curial.

- (1993): Col-locació de personatges en un jardí tancat, Barcelona, Columna.

- (2001): La dona d'aigua de Lanós. Contalles de Cerdanya, Canet de Rosselló, Trabucaire.

Cerdà, J.P. i A. Vinas (1997): Paraula fonda. Sens profond, Perpinyà, Publications de l'Olivier.

Manent, A. (1961): «Presentació de Jordi Pere Cerdà», dins Cerdà, J.P., Contalles de Cerdanya, Barcelona, Barcino, 5-7.

ORIOL, C. (2002): Introducció a l'etnopoètica: teoria i formes del folklore en la cultura catalana, Valls, Cossetània.

Oriol, C. (2011): «Les rondalles d'Enric Valor en el marc de la rondallística catalana», LLuCh, G. i J.M. BALDAQuí (eds.): Nova reflexió sobre l'obra d'Enric Valor, Alacant, Institut Interuniversitari de Filologia Valenciana, 95-109.

RAmuZ, C.F. (1992): «Lettre à Bernard Grasset», Deux Lettres, Lausana, Éditions l'Âge d'Homme, 23-66.

SALVAdor, V. (2012): Figures i esbossos. Estudis sobre literatura valenciana contemporània, Alacant, Institut Alacantí de Cultura Juan Gil Albert.

Verdaguer, P. (1966): «Introducció», dins Cerdì, J.P. Obra poètica, Barcelona, Barcino, 5-62.

Vinas, A. (2000): «De la Cerdagne à Jordi Pere Cerdà», dins Cerdà, J.P. Suite cerdana, Perpinyà, Publications de l'Olivier, 9-21.

Woods, Peter (1993): Critical events in teaching and learning, Londres, The Falmer Press. 


\section{BIONOTA}

Josep Marqués Meseguer. Doctorand contractat en Estudis catalans i transfronterers a la Universitat de Perpinyà Via Domícia, en cotutela amb la Universitat Jaume I (Castelló de la Plana). Actualment prepara la tesi amb títol Espai i identitat en l'obra de Jordi Pere Cerdà. Per una geografia literària cerdaniana. També ha estat professor de català al lectorat de l'Université de Picardie Jules Verne (Amiens, França) del 2009 al 2014, on alhora va cursar el Màster en Literatura antiga, francesa i comparada. 